\title{
Delayed Effects of Early Stress on Hippocampal Development
}

\author{
Susan L Andersen*, ${ }^{*, 2}$ and Martin H Teicher ${ }^{1,2}$ \\ 'Developmental Psychopharmacology Laboratory, Department of Psychiatry, Harvard Medical School, Belmont, MA, USA; ${ }^{2}$ McLean Hospital, \\ Belmont, MA, USA
}

\begin{abstract}
Early maternal separation has been shown in animal models to produce enduring morphological changes in the hippocampus and other brain structures, which may not become evident until adulthood. Postnatally, the trajectory of overproduction and pruning of axons, dendrites, synapses and receptors shapes the brain between puberty and adulthood. The objective of the study was to ascertain whether this normal trajectory was affected by repeated maternal separation. Rat pups were separated from their mother for $4 \mathrm{~h}$ a day between postnatal days 2 and 20 (ISO group), and compared to rat pups that remained with their mother in the animal facilities (AFR group) and were exposed to minimal handling. Immunoreactivity to synaptophysin was quantified in the hippocampus CAI and CA3, amygdala, and prefrontal cortex using optical densitometry (OD) at 25, 40, 60, 80, and 100 days in male and female rats. Synaptophysin OD increased dramatically in CAI and CA3 between 25 and 60 days in the AFR group and fell by the same degree between 60 and 100 days, showing the expected sequence of overproduction and pruning. No difference between groups in synaptophysin OD was observed at 25 and 40 days. However, at day 60 synaptophysin was 34-36\% lower in CAI and CA3 of the ISO group, and remained 24-26\% lower at I00 days. Early isolation produced no enduring reduction in synaptophysin OD in the amygdala or prefrontal cortex. Overall, these results suggest that early maternal separation produced a regionally specific delayed effect on the structure of the hippocampus by attenuating rates of synaptic development.

Neuropsychopharmacology (2004) 29, 1988-1993, advance online publication, 18 August 2004; doi: I0.1038/sj.npp. 1300528
\end{abstract}

Keywords: adolescence; limbic; maternal separation; pruning; stress; synaptophysin

\section{INTRODUCTION}

Early stress has been shown in animal models to produce enduring morphological changes in the hippocampus and other brain structures (McEwen, 2000b). Childhood abuse has been associated with reduction in hippocampal volume in adults (Bremner et al, 1997; Driessen et al, 2000; Stein et al, 1997; Vythilingam et al, 2002), but not children (De Bellis et al, 2001, 1999; Carrion et al, 2001). Can early maternal separation produce delayed effects on brain morphology by altering normal developmental trajectories? Prior to puberty, there is a marked overproduction of axons, dendrites, synapses, and receptors (Rakic, 1991). This is followed by a period of rapid pruning and elimination between puberty and adulthood. Up to $50 \%$ of synapses and receptors are lost in both cortical (Andersen et al, 2000; Huttenlocher, 1979; Lidow et al, 1991) and subcortical regions (Seeman et al, 1987; Teicher et al, 1995). The time course and degree of pruning, however, varies between regions (Andersen et al, 2000; Huttenlocher, 1979;

\footnotetext{
*Correspondence: Dr SL Andersen, McLean Hospital, I I 5 Mill Street, Belmont, MA 02478, USA, Tel: + | 61785532 II, Fax: + | 617855 3479, E-mail: andersen @mclean.org

Received 13 August 2003; revised 24 May 2004; accepted 4 June 2004 Online publication: 21 June 2004 at http://www.acnp.org/citations/ Npp062 10403368/default.pdf
}

Teicher et al, 1995). Virtually nothing is known about the effects of maternal separation on this process.

The hippocampus is a brain region that appears to be especially vulnerable to the effects of stress. This region has protracted development (Benes et al, 1994; Giedd et al, 1996), and also has a high density of glucocorticoid receptors in rats. Early exposure to stress or corticosteroids can cause hippocampal remodeling (or atrophy (Sapolsky, 2000)), and is associated with decreases in dendritic branching, vulnerability to subsequent insult, and neurogenesis (Gould et al, 2000). High levels of glucocorticoids can be directly neurotoxic to hippocampal pyramidal cells (Sapolsky et al, 1991, 1990). Much less is known about the effects of early experience on the development of the prefrontal cortex and the amygdala. The prefrontal cortex has a very protracted ontogeny (Alexander and Goldman, 1978) and is specifically activated by stressors (Bannon and Roth, 1983; Deutch et al, 1991), and in primates may have a higher density of glucocorticoid receptors than the hippocampus (Sanchez et al, 2000). We have hypothesized that exposure to early maternal separation could affect prefrontal cortical development, possibly resulting in accelerated but attenuated development (Teicher et al, 1997). Finally, glucocorticoid receptors are present in the amygdala (Peiffer et al, 1991), and maternal separation produces enduring effects on the neurochemical structure of this region (Caldji et al, 1998; Barna et al, 2003; Ploj et al, 
2003a,b). The amygdala plays an integral role in stress responsiveness both directly via changes in the benzodiazepine system (Caldji et al, 1998) and indirectly via its corticotropin-releasing hormone $(\mathrm{CRH})$ projections to the locus ceruleus. Changes in maternal care are already reported to increase the $\mathrm{CRH} \mathrm{mRNA}$ in the amygdala (Barna et al, 2003). However, whether early maternal separation can program (or 'direct') synaptic overproduction and elimination during adolescence has never been examined.

The aim of the present study was to test the hypothesis that exposure to early maternal separation exerts enduring effects on brain structure by altering either the degree or time course of synaptic overproduction and pruning in the hippocampus, amygdala, and prefrontal cortex. In addition to their apparent sensitivity, these regions were also selected given their importance in memory, executive function, and emotional regulation.

\section{MATERIALS AND METHODS}

\section{Subjects}

Female multiparous Sprague-Dawley rats (250-275 g, Charles River Laboratories, Wilmington, MA) were bred at McLean Hospital. The day of birth was designated as postnatal day 0 (P0). At 2 days after birth, the litters were culled to 10 pups (five males and five females), and litters were randomly assigned to either an isolation/maternal separation (ISO Group) or animal facility reared group (AFR Group). Pups in the ISO Group were weighed every day and isolated for $4 \mathrm{~h}$ per day between P2 and 20, and kept at thermoneutral temperature. This procedure is similar to procedures used by other laboratories (Liu et al, 2000; Plotsky and Meaney, 1993). Pups in the AFR Group were not disturbed after day 2, except for routine weekly changes in cage bedding.

Rats were weaned on day 22-23, and group-housed in same-sex caging until the time of killing. Animals were sacrificed at P25, 40,60, 80, and $100 \pm 2$ days, as females were always sacrificed in diestrus, which is consistent with our previous studies (Andersen, 2002; Andersen et al, 1997) and represents the phase when stress responsiveness may be at its highest point (Figueiredo et al, 2002). The selection of ages is based on stages corresponding to childhood, adolescence, young adulthood, and adulthood (Andersen, 2003). An average of $n=5-7$ rats per condition and sex were used. Data were subsequently collapsed across sex as it did not significantly exert an effect on condition or age.

\section{Perfusion, Histology, and Immunohistochemical Staining}

At the appropriate age, subjects were transcardially perfused under sodium pentabarbital anesthesia with $4 \%$ paraformaldehyde (PFA), $\mathrm{pH}$ 7.4. The brains were removed and post-fixed in $4 \%$ PFA solution overnight, then cryoprotected in $20 \%$ sucrose in phosphate-buffered saline. Free-floating coronal sections $(40 \mu \mathrm{m})$ were carefully matched for anatomical location to assure comparison of comparable regions of interest across conditions. Immunoreactivity to synaptophysin, a protein associated with synapses, was used as a our dependent measure (Glantz and Lewis, 1997). Slices were stained for synaptophysin (SVP38, $1: 1000$, Sigma Chemical, St Louis, MO), processed using the standard avidin-biotin technique, and visualized with DAB. Each staining 'run' contained all ages and conditions to account for inter-run variability. Moreover, data were blanked to synaptophysin staining in the corpus callosum within each subject.

\section{Data Analysis}

Densitometric analysis of SVP38 was carried out using module IV of the MCID System (Imaging Research Inc., Ontario, Canada) interfaced with a Leica DMRB light microscope, at $\times 5$ magnification, and a Sony CCD camera (model XC 77). For the hippocampal, amygdalar, and prefrontal cortex regions, a box of approximately 2000 pixels was used and placed in the center of the structure. A representative staining is shown in Figure 1. Three measurements were taken for each region, for each hemisphere, plus a background measure. Thus, data for each subject were represented by the average OD of the three sections corrected by the background.

Data were analyzed with ANOVA (SYSTAT, Evanston, IL) with condition, age, and sex as between-subject factors. Percent differences between the isolation-reared and animal facility-reared groups were presented as mean \pm SEM, with the SEM corrected for the variability in both the experimental and control groups (McLean and Welch, 1971). Sex did not exert any significant effects within these analyses ( $p$ 's $>0.1$ ), therefore data were collapsed across this variable for all subsequent analyses.

\section{RESULTS}

Early maternal separation produced significant changes in expression of synaptophysin in the hippocampus and amygdala, but not the prefrontal cortex. Early maternal separation effects on synaptophysin OD in the hippocam-

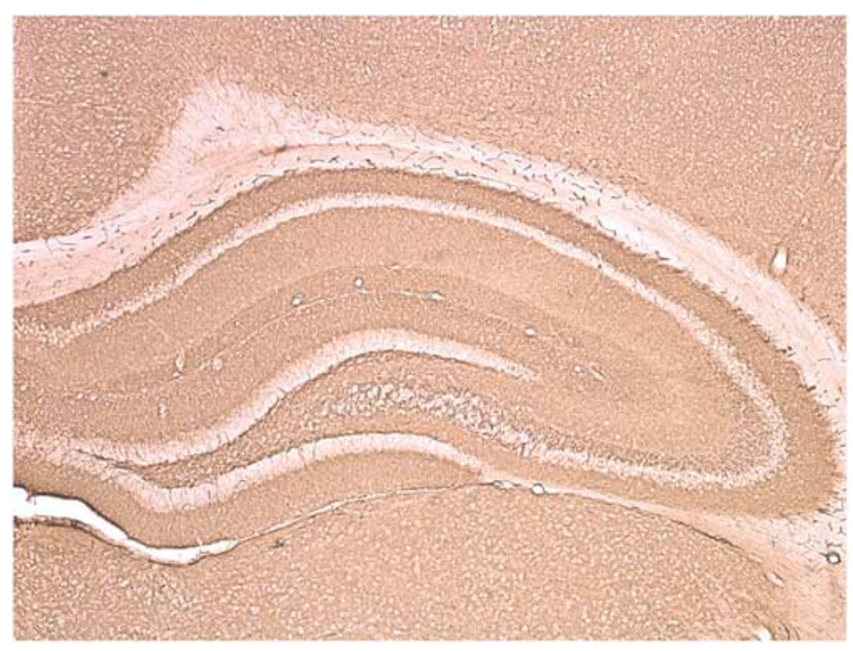

Figure I Photomicrograph of the hippocampus stained with synaptophysin $(1: 1000)$ and visualized with DAB. This image was taken at $\times 5$ magnification. Data measurements are based on a box of approximately 2000 pixels. 
pus, but not the amygdala, persisted to the eldest age studied (P100).

\section{Hippocampus}

The hippocampus was subdivided into CA1 and CA3 subregions, with both regions demonstrating similar effects. A major effect of isolation stress was observed in CA1 $(\mathrm{F}(1,135)=7.75, \quad p<0.006)$ and $\mathrm{CA} 3 \quad(\mathrm{~F}(1,135)=10.02$, $p<0.002)$. Overall synaptophysin was reduced by $17.8 \%$ in CA1 and $16.0 \%$ in CA3. As illustrated in Figure 2, the effect of isolation stress emerged at 60 days of age. There were no differences between groups at 25 days $(\mathrm{CA} 1: \mathrm{F}(1,32)=0.56$, $p>0.4$; CA3: $\mathrm{F}(1,32)=1.03, p>0.3)$ or 40 days (CA1: $\mathrm{F}(1,28)=0.55, p>0.4 ; \mathrm{CA} 3: \mathrm{F}(1,28)=0.19, p>0.6)$ of age. However, at day 60 synaptophysin immunoreactivity was reduced by $33.7 \%(\mathrm{~F}(1,24)=14.84, p=0.0008)$ in $\mathrm{CA} 1$ and by $35.8 \% \quad(\mathrm{~F}(1,24)=14.88, \quad p=0.0008)$ in CA3. This difference persisted at day 100 , the oldest age evaluated (CA1: $26.4 \%$ reduction, $\mathrm{F}(1,36)=6.30, p=0.02$; $\mathrm{CA} 3: 24.3 \%$ reduction, $\mathrm{F}(1,36)=5.12, p=0.03)$.

Evidence for overproduction and pruning was apparent in the AFR group but not the ISO group. Synaptophysin immunoreactivity in CA1 increased by a significant
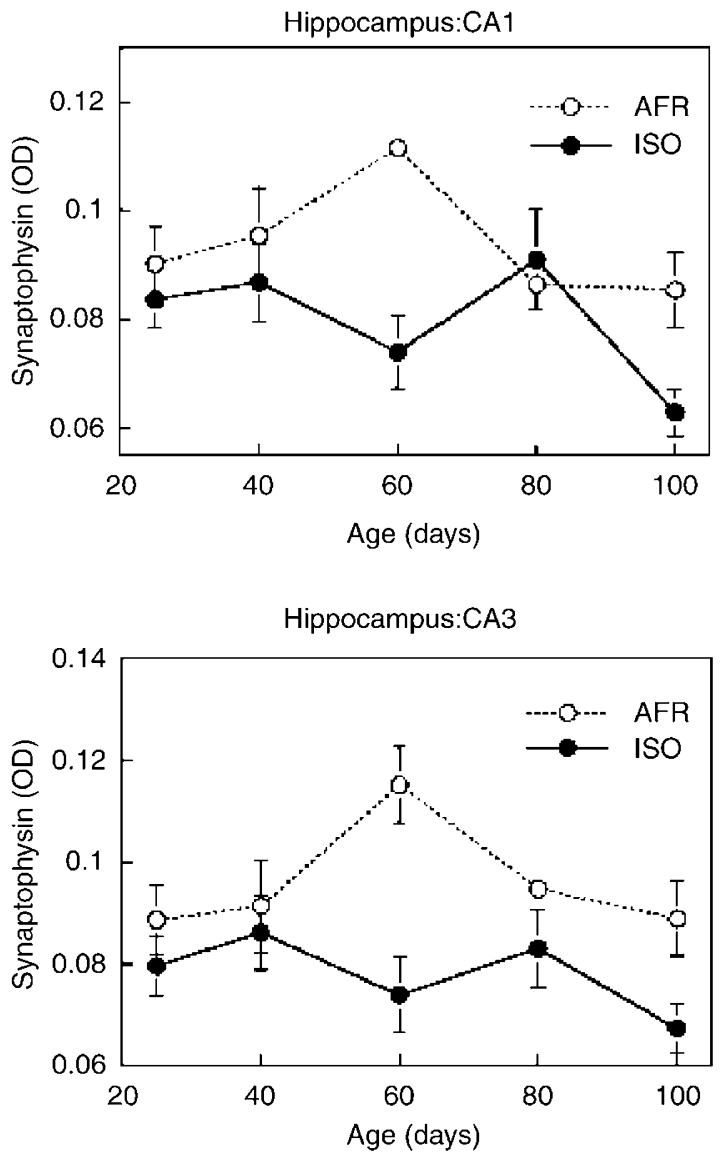

Figure 2 Region of interest analysis of synaptophysin immunolabeling of CAI (top) and CA3 (lower) of the hippocampus in animal facility reared (AFR; open circles) or isolation (ISO; closed circles) animals across 25, 40, 60,80 , and 120 days of age. Mean \pm SEM are presented; average $n=10-14$ animals at each age.
$23.6 \pm 13.2 \%$ between P25 and $60(\mathrm{t}(30)=2.14, p<0.05)$ before falling by $23.4 \pm 7.3 \%$ by $\mathrm{P} 100(\mathrm{t}(34)=2.51, p<0.02$ in the AFR group. In contrast, the ISO group had a nonsignificant drop of $11.6 \pm 10.3 \%(\mathrm{t}(26)=1.12, p>0.2)$ between 25 and 60 days, and a further nonsignificant decline between 60 and $100 \quad(15.0 \pm 9.0 \%$ reduction, $\mathrm{t}(26)=1.43, p=0.2)$.

Similarly, synaptophysin immunoreactivity in CA3 increased by $29.9 \pm 14.0 \%$ between P25 and $60(\mathrm{t}(30)=2.63$, $p<0.01)$ and fell by $22.8 \pm 7.5 \%$ between P60 and P100 $(\mathrm{t}(34)=2.40, p<0.02)$ in the AFR group. The ISO group showed a slight fall in synaptophysin immunoreactivity between 25 and 60 days $(7.1 \pm 12.2 \%, \mathrm{t}(26)=0.61, p>0.5)$, and a further nonsignificant decline between 60 and 100 $(8.9 \pm 10.4 \%$ reduction, $\mathrm{t}(26)=0.76, p>0.4)$.

\section{Amygdala}

Quantification of synaptophysin OD in the amygdala (Figure 3a) also revealed significant effects of isolation stress $(\mathrm{F}(1,135)=4.09, p<0.05)$, resulting in a modest $6.2 \pm 3.0 \%$ reduction in OD. There was a major effect of age $(\mathrm{F}(4,135)=5.55, p=0.004)$, which was seen in both groups as a marked increase in synaptophysin after P25. Between 25 and 60 days, synaptophysin OD increased by $16.1 \pm 8.7 \%(\mathrm{t}(30)=2.12, p<0.05)$ in the AFR group, and
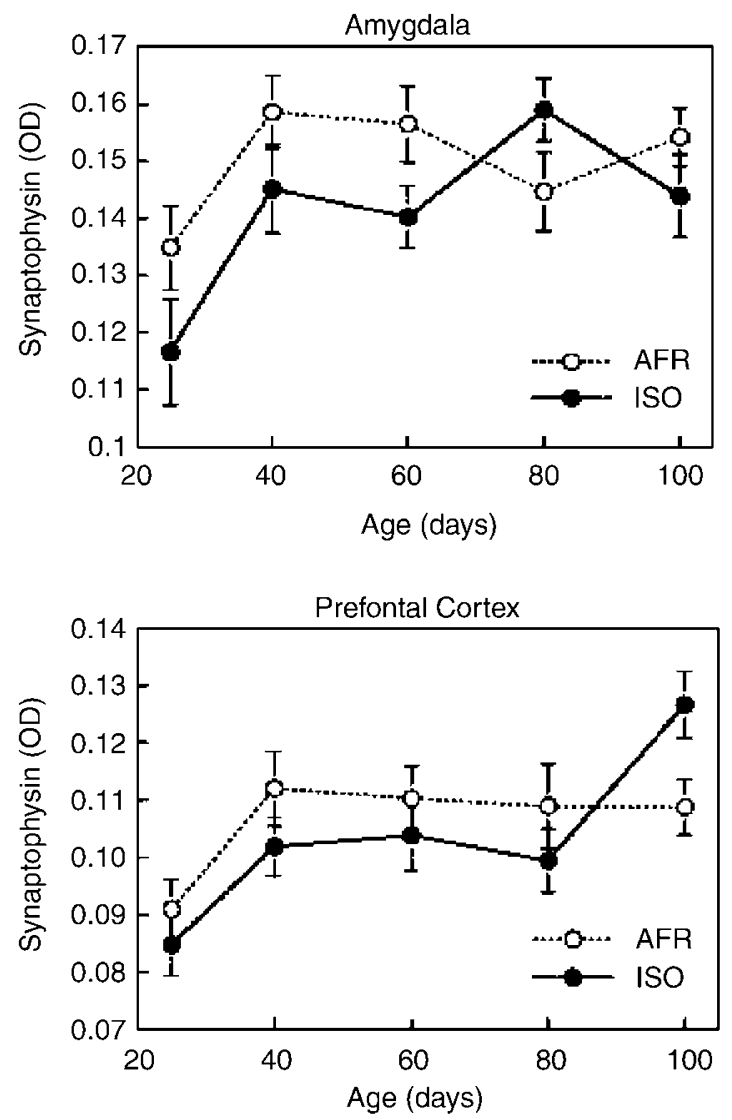

Figure 3 Region of interest analysis of synaptophysin immunolabeling of the amygdala (top) and the prefrontal cortex (lower) in animal facility reared (AFR; open circles) or isolation (ISO; closed circles) animals across $25,40,60,80$, and 120 days of age. Mean \pm SEM are presented; average $n=10-14$ animals at each age. 
increased by $20.3 \pm 12.0 \%(\mathrm{t}(26)=2.01, p=0.05)$ in the ISO group. However, in contrast to the hippocampus, there was no decline between 60 and 100 days. Synaptophysin OD on day 100 was within $3 \%$ of day 60 values for the AFR groups $(\mathrm{t}(34)=0.27, p>0.7)$ and the ISO group $(\mathrm{t}(26)=0.38$, $p>0.7)$.

\section{Prefrontal Cortex}

Unlike the hippocampus and amygdala, there was no significant main effect of isolation stress $(\mathrm{F}(1,122)=0.59$, $p>0.4)$. There was, however, a major effect of age $(\mathrm{F}(4,122)=7.85, p=0.00001)$. Both groups had a marked rise in synaptophysin OD after P25. On average, OD was $21.7 \pm 7.6 \%$ greater on day 60 than day 25 . Between days 25 and 80 , there was a trend for synaptophysin OD to be lower in the ISO group than the AFR group $(7.6 \pm 3.9 \%$ reduction, $\mathrm{t}(108)=1.80, p=0.07)$. However, at P100 synaptophysin OD was $16.1 \pm 6.8 \%(\mathrm{t}(36)=2.98, p=0.005)$ greater in the ISO animals than in the AFR group.

\section{DISCUSSION}

The results of this study suggest that early maternal separation had two main effects. First, early maternal separation reduced the overall synaptophysin levels in hippocampus relative to the AFR control groups. Second, and perhaps of greater interest, is the time course and nature of the effect. Early maternal separation appeared to prevent the normal overproduction of synapses in hippocampus, but not the amygdala or prefrontal cortex. This time-course difference has never been demonstrated previously, as other studies have examined only adult systems to illustrate the impact of stress (de Kloet et al, 1996; Lehmann et al, 2002; Matthews et al, 2001). Together, these data suggest that early maternal separation has protracted regionally specific effects that occur long after the stressor has been removed.

The finding of protracted isolation effects is in stark contrast to the effects in adult animals, where dendritic remodeling within the hippocampus reverses within 7-10 days after removal of 21 days restraint stress (McEwen, 2000a). The data presented in Figure 2 suggest that early life events set in motion a series of adverse events that lead to the progressive loss of hippocampal synapses rather than an immediate loss of density. Moreover, the effect of early maternal separation persisted for at least 80 days after cessation of the stressor.

These observations provide a possible explanation for the observation that childhood abuse has been found to be associated with reduced hippocampal volume in adults (Bremner et al, 1997; Driessen et al, 2000; Stein et al, 1997; Vythilingam et al, 2002), but not children (De Bellis et al, 2001, 1999; Carrion et al, 2001). Based on these findings, early stress-induced alterations in human hippocampal size should not be apparent until at least early adulthood.

While early maternal separation was associated with persistent decrease in synaptophysin OD in the hippocampus, this was not the case in either the amygdala or prefrontal cortex. Further, early maternal separation appeared to exert a dramatic suppressive effect on synaptic overproduction in the hippocampus, but did not appear to affect this process in the other brain regions. This suggests that there may be important regional differences in the factors that regulate the trajectories of synaptic development.

Interestingly, the effects of early maternal separation on synaptophysin immunoreactivity in the hippocampus may be the first evidence of any environmental influence on the normal developmental process of overproduction and pruning in a nonsensory system. We had previously reported that neither the postnatal removal of gonadal hormones (Andersen et al, 2002) nor chronic antagonism of NMDA receptors by MK-801 (Teicher et al, 2003) affected the overproduction and pruning of dopamine receptors in the striatum. This study measured synaptophysin, which may be under different regulatory control. It is unlikely that gonadal hormones play a significant role in decreased synaptophysin because no sex differences were observed. The role of glutamate, however, cannot be ruled out with certainty in this study. Glutamate mediates activitydependent pruning of dendrites and synapses via NMDA receptor activation and calcium influx in a number of brain regions, including the sensorimotor cortex and the cortex (Kozlowski et al, 1997; Nelson et al, 1990; Rabacchi et al, 1992). Studies examining the influence of MK-801 administration during the overproduction and pruning phase in animals with a history of maternal separation are ongoing.

The opposite approach may also be taken: increased maternal interactions in the AFR group may offer some form of protection relative to those in the ISO group. Studies on maternal arched back nursing from Meaney's group strongly suggest that greater attention by the dam mediates enhanced resiliency in the pups later in life by programming the HPA system through the GABA (Caldji et $a l, 1998$ ) and arginine-vasopressin systems (Anisman et al, 1998). Part of this resiliency may be mediated by the 'normal' overproduction and pruning of synapses during adolescence, which was observed in synaptophysin measures in the AFR group.

One limitation of the present study is the estimation of synaptic density using synaptophysin immunoreactivity quantified by optical densitometry. Electron microscopy has been used as a definitive technique to quantify synapse numbers or density, but this approach is costly, labor intensive, and technically difficult (Calhoun et al, 1996). Synaptophysin-based techniques have been used with increasing frequency to estimate synaptic density in clinical (Eastwood et al, 1995; Glantz and Lewis, 1997; Vawter et al, 2002) and preclinical studies (Mazer et al, 1997; Saito et al, 1994). While several studies have used optical density as a means of analyzing immunohistochemical preparations (Glantz and Lewis, 1997), great care needs to be taken to provide very consistent levels of staining across conditions and across analytical runs. We carefully matched samples and counterbalanced all ages and conditions between analytical runs to avoid potential confounding effects. Our methodology was sufficiently rigorous and robust to detect important developmental differences in synaptophysin OD in controls that were in accord with Golgi studies (Norrholm and Ouimet, 2000). Stereological assessment of synaptophysin-labeled presynaptic boutons may provide an even better estimate of synaptic density than optical 
densitometry (Calhoun et al, 1996), and these findings should be verified using alternative quantitative techniques and additional markers.

Overall, these findings show that early isolation maternal separation exerts an enduring effect on hippocampal development, and suggest that the effect may be timedependent and arises as a consequence of an arrested phase of synaptic overproduction. Enduring alterations in synapse formation in the hippocampus may provide a new understanding for the enhanced vulnerability of individuals with a history of childhood abuse to develop depression (Heim and Nemeroff, 2001; Putnam, 2003; Teicher, 2002; Wise et al, 2001) or post-traumatic stress disorder (Robin et al, 1997; Yehuda et al, 2001; Zaidi and Foy, 1994) later in life.

\section{ACKNOWLEDGEMENTS}

We are extremely thankful for excellent technical assistance by Celeste LeBlanc and Nathalie Dumont. We would like to thank Dr Rachel Neve for the generous use of her microscope. This work was funded by the National Institute of Health (MH-53636) to MHT.

\section{REFERENCES}

Alexander GE, Goldman PS (1978). Functional development of the dorsolateral prefrontal cortex: an analysis utlizing reversible cryogenic depression. Brain Res 143: 233-249.

Andersen S (2002). Changes in the second messenger cyclic AMP during development may underlie motoric symptoms in Attention Deficit/Hyperactivity Disorder (ADHD). Behav Brain Res 130: 197-201.

Andersen S (2003). Trajectories of brain development: point of vulnerability or window of opportunity? Neurosci Biobehav Rev 27: 3-18.

Andersen S, Thompson A, Krenzel E, Teicher M (2002). Pubertal changes in gonadal hormones do not underlie adolescent dopamine receptor overproduction. Psychoneuroendocrinology 27: 683-691.

Andersen SL, Rutstein M, Benzo JM, Hostetter JC, Teicher MH (1997). Sex differences in dopamine receptor overproduction and elimination. Neuroreport 8: 1495-1498.

Andersen SL, Thompson AT, Rutstein M, Hostetter JC, Teicher MH (2000). Dopamine receptor pruning in prefrontal cortex during the periadolescent period in rats. Synapse 37: 167-169.

Anisman H, Zaharia MD, Meaney MJ, Merali Z (1998). Do earlylife events permanently alter behavioral and hormonal responses to stressors? Int J Dev Neurosci 16: 149-164.

Bannon MJ, Roth RH (1983). Pharmacology of mesocortical dopamine neurons. Pharmacol Rev 35: 53-68.

Barna I, Balint E, Baranyi J, Bakos N, Makara GB, Haller J (2003). Gender-specific effect of maternal deprivation on anxiety and corticotropin-releasing hormone mRNA expression in rats. Brain Res Bull 62: 85-91.

Benes FM, Turtle M, Khan Y, Farol P (1994). Myelination of a key relay zone in the hippocampal formation occurs in the human brain during childhood, adolescence, and adulthood. Arch Gen Psychiatry 51: 477-484.

Bremner JD, Randall P, Vermetten E, Staib L, Bronen RA, Mazure $C$ et al (1997). Magnetic resonance imaging-based measurement of hippocampal volume in posttraumatic stress disorder related to childhood physical and sexual abuse - a preliminary report. Biol Psychiatry 41: 23-32.

Caldji C, Tannenbaum B, Sharma S, Francis D, Plotsky PM, Meaney MJ (1998). Maternal care during infancy regulates the development of neural systems mediating the expression of fearfulness in the rat. Proc Natl Acad Sci USA 95: 5335-5340.

Calhoun ME, Jucker M, Martin LJ, Thinakaran G, Price DL, Mouton PR (1996). Comparative evaluation of synaptophysinbased methods for quantification of synapses. J Neurocytol 25: 821-828.

Carrion VG, Weems CF, Eliez S, Patwardhan A, Brown W, Ray RD et al (2001). Attenuation of frontal asymmetry in pediatric posttraumatic stress disorder. Biol Psychiatry 50: 943-951.

De Bellis MD, Hall J, Boring AM, Frustaci K, Moritz G (2001). A pilot longitudinal study of hippocampal volumes in pediatric maltreatment-related posttraumatic stress disorder. Biol Psychiatry 50: 305-309.

De Bellis MD, Keshavan MS, Clark DB, Casey BJ, Giedd JN, Boring AM et al (1999). A.E. Bennett research award. Developmental traumatology. Part II: Brain development (see comments). Biol Psychiatry 45: 1271-1284.

de Kloet ER, Rots NY, Cools AR (1996). Brain-corticosteroid hormone dialogue: slow and persistent. Cell Mol Neurobiol 16: 345-356.

Deutch AY, Lee MC, Gillham MH, Cameron DA, Goldstein M, Iadarola MJ (1991). Stress selectively increases fos protein in dopamine neurons innervating the prefrontal cortex. Cereb Cortex 1: 273-292.

Driessen M, Herrmann J, Stahl K, Zwaan M, Meier S, Hill A et al (2000). Magnetic resonance imaging volumes of the hippocampus and the amygdala in women with borderline personality disorder and early traumatization. Arch Gen Psychiatry 57: $1115-1122$.

Eastwood SL, Burnet PW, Harrison PJ (1995). Altered synaptophysin expression as a marker of synaptic pathology in schizophrenia. Neuroscience 66: 309-319.

Figueiredo HF, Dolgas CM, Herman JP (2002). Stress activation of cortex and hippocampus is modulated by sex and stage of estrus. Endocrinology 143: 2534-2540.

Giedd JN, Vaituzis AC, Hamburger SD, Lange N, Rajapakse JC, Kaysen D et al (1996). Quantitative MRI of the temporal lobe, amygdala, and hippocampus in normal human development: ages 4-18 years. J Comp Neurol 366: 223-230.

Glantz LA, Lewis DA (1997). Reduction of synaptophysin immunoreactivity in the prefrontal cortex of subjects with schizophrenia. Regional and diagnostic specificity. Arch Gen Psychiatry 54: 660-669.

Gould E, Tanapat P, Rydel T, Hastings N (2000). Regulation of hippocampal neurogenesis in adulthood. Biol Psychiatry 48: 715-720.

Heim C, Nemeroff CB (2001). The role of childhood trauma in the neurobiology of mood and anxiety disorders: preclinical and clinical studies. Biol Psychiatry 49: 1023-1039.

Huttenlocher PR (1979). Synaptic density in human frontal cortex-developmental changes and effects of aging. Brain Res 163: 195-205.

Kozlowski DA, Hilliard S, Schallert T (1997). Ethanol consumption following recovery from unilateral damage to the forelimb area of the sensorimotor cortex: reinstatement of deficits and prevention of dendritic pruning. Brain Res 763: 159-166.

Lehmann J, Pryce CR, Jongen-Relo AL, Stohr T, Pothuizen HH, Feldon J (2002). Comparison of maternal separation and early handling in terms of their neurobehavioral effects in aged rats. Neurobiol Aging 23: 457-466.

Lidow MS, Goldman-Rakic PS, Rakic P (1991). Synchronized overproduction of neurotransmitter receptors in diverse regions of the primate cerebral cortex. Proc Natl Acad Sci USA 88: 10218.

Liu D, Caldji C, Sharma S, Plotsky PM, Meaney MJ (2000). Influence of neonatal rearing conditions on stress-induced adrenocorticotropin responses and norepinepherine release in the hypothalamic paraventricular nucleus. J Neuroendocrinol 12: 5-12. 
Matthews K, Dalley JW, Matthews C, Tsai TH, Robbins TW (2001). Periodic maternal separation of neonatal rats produces regionand gender-specific effects on biogenic amine content in postmortem adult brain. Synapse 40: 1-10.

Mazer C, Muneyyirci J, Taheny K, Raio N, Borella A, WhitakerAzmitia P (1997). Serotonin depletion during synaptogenesis leads to decreased synaptic density and learning deficits in the adult rat: a possible model of neurodevelopmental disorders with cognitive deficits. Brain Res 760: 68-73.

McEwen BS (2000a). Allostasis and allostatic load: implications for neuropsychopharmacology. Neuropsychopharmacology 22: 108-124.

McEwen BS (2000b). The neurobiology of stress: from serendipity to clinical relevance. Brain Res 886: 172-189.

McLean R, Welch B (1971). A common error in assessing the significance of percentage change in neuropharmacology. $J$ Pharm Pharmacol 23: 643-646.

Nelson PG, Fields RD, Yu C, Neale EA (1990). Mechanisms involved in activity-dependent synapse formation in mammalian central nervous system cell cultures. J Neurobiol 21: 138-156.

Norrholm SD, Ouimet CC (2000). Chronic fluoxetine administration to juvenile rats prevents age-associated dendritic spine proliferation in hippocampus. Brain Res 883: 205-215.

Peiffer A, Barden N, Meaney MJ (1991). Age-related changes in glucocorticoid receptor binding and mRNA levels in the rat brain and pituitary. Neurobiol Aging 12: 475-479.

Ploj K, Roman E, Nylander I (2003a). Long-term effects of maternal separation on ethanol intake and brain opioid and dopamine receptors in male Wistar rats. Neuroscience 121: 787-799.

Ploj K, Roman E, Nylander I (2003b). Long-term effects of short and long periods of maternal separation on brain opioid peptide levels in male Wistar rats. Neuropeptides 37: 149-156.

Plotsky PM, Meaney MJ (1993). Early, postnatal experience alters hypothalamic corticotropin-releasing factor (CRF) mRNA, median eminence CRF content and stress-induced release in adult rats. Brain Res Mol Brain Res 18: 195-200.

Putnam FW (2003). Ten-year research update review: child sexual abuse. J Am Acad Child Adolesc Psychiatry 42: 269-278.

Rabacchi S, Bailly Y, Delhaye-Bouchaud N, Mariani J (1992). Involvement of the $N$-methyl D-aspartate (NMDA) receptor in synapse elimination during cerebellar development. Science 256: $1823-1825$.

Rakic P (1991). Development of the primate cerebral cortex. In: Lewis M (ed). Child and Adolescent Psychiatry. Williams and Wilkins: Baltimore.

Robin RW, Chester B, Rasmussen JK, Jaranson JM, Goldman D (1997). Prevalence and characteristics of trauma and posttraumatic stress disorder in a southwestern American Indian community. Am J Psychiatry 154: 1582-1588.

Saito S, Kobayashi S, Ohashi Y, Igarashi M, Komiya Y, Ando S (1994). Decreased synaptic density in aged brains and its prevention by rearing under enriched environment as revealed by synaptophysin contents. J Neurosci Res 39: 57-62.

Sanchez MM, Young LJ, Plotsky PM, Insel TR (2000). Distribution of corticosteroid receptors in the rhesus brain: relative absence of glucocorticoid receptors in the hippocampal formation. $J$ Neurosci 20: 4657-4668.

Sapolsky RM (2000). Glucocorticoids and hippocampal atrophy in neuropsychiatric disorders. Arch Gen Psychiatry 57: 925-935.

Sapolsky RM, Stein-Behrens BA, Armanini MP (1991). Long-term adrenalectomy causes loss of dentate gyrus and pyramidal neurons in the adult hippocampus. Exp Neurol 114: 246-249.

Sapolsky RM, Uno H, Rebert CS, Finch CE (1990). Hippocampal damage associated with prolonged glucocorticoid exposure in primates. J Neurosci 10: 2897-2902.

Seeman P, Bzowej NH, Guan HC, Bergeron C, Becker LE, Reynolds GP et al (1987). Human brain dopamine receptors in children and aging adults. Synapse 1: 399-404.

Stein MB, Koverola C, Hanna C, Torchia MG, McClarty B (1997). Hippocampal volume in women victimized by childhood sexual abuse. Psychol Med 27: 951-959.

Teicher MH (2002). Scars that won't heal: the neurobiology of child abuse. Sci Am 286: 68-75.

Teicher MH, Andersen SL, Hostetter Jr JC (1995). Evidence for dopamine receptor pruning between adolescence and adulthood in striatum but not nucleus accumbens. Brain Res Dev Brain Res 89: $167-172$.

Teicher MH, Ito Y, Glod CA, Andersen SL, Dumont N, Ackerman E (1997). Preliminary evidence for abnormal cortical development in physically and sexually abused children using EEG coherence and MRI. Ann N Y Acad Sci 821: 160-175.

Teicher MH, Krenzel E, Thompson AP, Andersen SL (2003). Dopamine receptor pruning during the peripubertal period is not attenuated by NMDA receptor antagonism in rat. Neurosci Lett 339: 169-171.

Vawter MP, Thatcher L, Usen N, Hyde TM, Kleinman JE, Freed WJ (2002). Reduction of synapsin in the hippocampus of patients with bipolar disorder and schizophrenia. Mol Psychiatry 7: 571-578.

Vythilingam M, Heim C, Newport J, Miller AH, Anderson E, Bronen $\mathrm{R}$ et al (2002). Childhood trauma associated with smaller hippocampal volume in women with major depression. $A m \mathrm{~J}$ Psychiatry 159: 2072-2080.

Wise LA, Zierler S, Krieger N, Harlow BL (2001). Adult onset of major depressive disorder in relation to early life violent victimisation: a case-control study. Lancet 358: 881-887.

Yehuda R, Hallig SL, Grossman R (2001). Childhood trauma and risk for PTSD: relationship to intergenerational effects of trauma, parental PTSD, and cortisol excretion. Dev Psychopathol 13: 733-753.

Zaidi LY, Foy DW (1994). Childhood abuse experiences and combat-related PTSD. J Trauma Stress 7: 33-42. 